
(1981-1987)

\author{
The origins of the political conceptions of kichnerism. The political experience \\ of the Ateneo Juan Domingo Perón in the Santa Cruz province (1981-1987)
}

\section{Pamela Sosa}

Pamela Sosa es becaria posdoctoral del Consejo Nacional de Investigaciones Científicas y Técnicas, Departamento de la carrera de Sociología, Facultad de Humanidades y Ciencias de la Universidad Nacional del Litoral, Argentina.

E-mail: pamesosa@hotmail.com

\section{resumen}

El Frente para la Victoria, la fuerza política que gobierna la Argentina desde el año 2003 hasta la actualidad, surgió como fuerza política en el año 1998 en la provincia de Santa Cruz, a partir de la conformación del sublema "Frente para la Victoria Santacruceña”. Usualmente se señala el gobierno de Néstor Kirchner de la intendencia de Río Gallegos (capital de la provincia) como el principal antecedente de la conformación de la misma. Este artículo muestra la experiencia política de los principales dirigentes de aquella organización en el Ateneo Juan Domingo Perón entre 1981 y 1987, antes de ingresar a las estructuras del Estado municipal. En contraste con los estudios que señalan que los partidos se conforman en el locus de las estructuras estatales, este artículo muestra que las principales concepciones políticas del kirchnerismo sobre cómo debe funcionar y construirse una organización, los principales rasgos de su identidad política -como su carácter militante- y sus posiciones ideológicas pragmáticas tuvieron origen antes de sus experiencias de gestión estatal y por fuera de las mismas. Las fuentes utilizadas para este trabajo fueron entrevistas semi estructuradas, revistas y diarios locales, diarios de sesiones parlamentarias, entre otros.

\section{palabras clave}

Ateneo J. D. Perón / peronismo / kirchnerismo / Frente para la Victoria / Santa Cruz

\section{summary}

Frente para la Victoria, the political force that governs Argentina since 2003 to today, arose as a political force in 1998 in the Santa Cruz province, from the creation of the motto "Frente para la Victoria Santacruceña". The tenure of Néstor Kirchner in the Río Gallegos (capital of the province) intendancy is usually pointed as the main precedent in the making of said motto. This article goes further back to showcase the political experience of the main political leaders from the organization in question in Ateneo Juan Domingo Perón between 1981 and 1987, before entering the municipal state structure. In contrast with previous studies which estate that parties are shape in the locus of state structures, this article demonstrates how the core political conceptions of kichnerism about how it must operate and build it self into an organization, the features of its political identity -its militant character- and its pragmatic political ideology have an origin before its experience of state management. The sources for this writing were semi-structured interviews, magazines and local newspapers, diaries of parliamentary sessions, among others.

\section{keywords}

Ateneo J. D. Perón / peronism / kirchnerism / Frente para la Victoria / Santa Cruz 


\section{Introducción}

Cuando se reflexiona desde espacios no académicos sobre la llegada de Néstor Kirchner a la presidencia de la Nación en el año 2003, y sobre su capacidad de sortear positivamente un contexto aún impregnado por la crisis de 2001, se recurre a explicaciones atravesadas por cierta genialidad, contingencia y destino. Muchos relatos han resaltado la gran perspicacia política de Néstor Kirchner así como también la combinación de una gran audacia y el cálculo racional como grandes virtudes para manejar los asuntos políticos en un contexto de gran incertidumbre social y política (Sarlo, 2011). Otros discursos, especialmente los de aquellos que conocen también su carrera política en Santa Cruz, codifican su trayectoria política en clave de suerte y sostienen que el "Lupo" siempre tuvo "culo", siempre "estuvo en el lugar justo, en el momento justo" (Garrone y Rocha, 2003; entrevistas realizadas por la autora). El presente artículo muestra los orígenes de un conjunto de concepciones políticas del kirchnerismo en la provincia de Santa Cruz en el Ateneo Juan Domingo Perón (Ateneo) a principios de la década de 1980, espacio y experiencia política que socializó a los provinciales dirigentes del Frente para la Victoria e influyó directamente en el perfil de la misma. A partir del análisis de esa experiencia es posible visibilizar que el carácter aleatorio, audaz -y a la vez racional-, que se le imputa a las acciones de los dirigentes de esta fuerza política no fue producto de la contingencia sino de un conjunto de formas de hacer y pensar la política que tuvo origen en las posiciones, relaciones y experiencias políticas que los principales dirigentes de la fuerza transitaron a principios de la década de 1980 en Santa Cruz. Como veremos, esta vivencia, le imprimió un conjunto de rasgos al Frente para la Victoria a nivel provincial (FVS) y nacional (FPV), entre ellos cierto carácter marginal, que le permitieron desenvolverse en espacios políticos y sociales atravesados por la desestructuración y, por esta razón, fuertemente contingentes.

Desde el punto de vista académico también se ha reflexionado sobre la trayectoria política del FPV en un contexto de crisis y desestructuración. En la misma tónica que las explicaciones ensayadas por fuera del ámbito académico, el debate sobre aquella problemática se condensó en el siguiente interrogante: ¿Cómo se explican los altos niveles de consenso y legitimidad de un actor político con credenciales asociadas a los denostados y fragmentados partidos, que llegó al poder con el $22 \%$ de los votos y asumió su gobierno luego de lo que pasó a la historia, en parte por la misma construcción realizada por este actor, como la peor crisis de la Argentina? Frente a esta pregunta, desde un primer grupo se enfatizó cómo el FPV fue estableciendo fronteras contingentes que, pese a que se fueron modificando, le permitieron constituir una identidad común que aglutinó esa fuerza política y generó de esa manera una relación de representación, pese a la heterogeneidad de intereses internos de la misma y el contexto de fragmentación social (Aboy Carlés, 2005; Rinesi y Vommaro, 2007; Rinesi, 2007; Yabkowski, 2012). Una segunda línea de análisis, lejos de reivindicar las formas de construcción política del FPV, especialmente el perfil fuertemente plebiscitario, delegativo y asentado en el apoyo y la representación de las mayorías, elemento valorizado por la perspectiva 
anterior, denuncian cierto perfil antidemocrático en la forma de construcción política y de legitimidad de esta organización. Sostienen que el FPV acentuó el diseño institucional de presidencialismo fuerte aplicado durante los gobiernos de Carlos Menem, esquema que concentró el poder político en el Ejecutivo en detrimento del resto de los poderes del Estado, instituciones en las que se ven representados los intereses de la sociedad (Serrafero, 2011; De Luca, 2011; Gargarella, 2011; Gervasoni, 2011; Levitsky y Murillo, 2008).

Pese a que a simple vista estas miradas presentan concepciones sobre la política $\mathrm{y}$ el poder que poseen grandes diferencias, todas han puesto de relieve un rasgo común que atraviesa la política del FPV: una relación distante con las instituciones, los grupos de representación y las tradiciones políticas. Todos han señalado que esta fuerza ha tenido un vínculo lejano con los partidos políticos y con formas de representación de carácter corporativo y ha privilegiado un lazo directo con las mayorías. De otra manera, coinciden en la tendencia delegativa de la fórmula democrática o, como también se ha denominado, fundacional, en el sentido que se presenta como una organización poco condicionada por las influencias del pasado y de la tradición que le impliquen una participación o compromiso con intereses que limiten su pretensión de representación directa. El presente artículo reconstruye el origen de estas formas y concepciones de hacer política a partir de la reconstrucción de la experiencia política de los principales dirigentes del Frente para la Victoria en Santa Cruz a principios de la década de 1980 en el Ateneo.

Para este el artículo se utilizaron datos extraídos de un corpus de 35 entrevistas semi estructuradas realizadas por la autora en los meses de marzo y noviembre de 2009 y 15 entrevistas de archivos periodísticos hechas en 1997 en Río Gallegos, ciudad capital de la provincia de Santa Cruz, y Pico Truncado, localidad situada al norte del territorio provincial. En segundo lugar, se consultó material periodístico producido a nivel provincial (Diarios La Opinión Austral y Correo del Sur y Revista Tesis), archivos partidarios y datos del Ministerio del Interior referenciados en el desarrollo del texto. Por último, también se recurrió a investigaciones periodísticas sobre el kirchnerismo, especialmente para la reconstrucción de las biografías de los principales referentes del Frente para la Victoria, (Gatti, 2003; Garrone y Rocha, 2003; Wornat, 2005; Cabot y Olivera, 2007; O’ Donnell, 2007; Amato y Boyanovsky Bazán, 2008; Majul, 2009; Di Matteo, 2009; Walger, 2010; Tenembaum, 2010; Miguez, 2011)

El artículo se organiza de la siguiente manera: en primer lugar se reconstruye la historia del Ateneo en la provincia de Santa Cruz y la trayectoria social y política de los principales dirigentes del FVS en ese espacio político. En segundo lugar, se describen las estrategias de representación de aquella fuerza política y sus consecuencias para el perfil de la organización, especialmente su carácter militante. En tercer lugar, se desarrollan las concepciones sobre la división de trabajo, las dinámicas de toma de decisión y las jerarquías internas. Por último, se describen y se analizan un conjunto de influencias de la experiencia del Ateneo en la conformación del perfil organizacional del Frente para la Victoria en Santa Cruz y a nivel nacional. 
La historia del Ateneo muestra la conformación de lo que podríamos denominar el habitus del desintegrado: el que se percibe por fuera de los vínculos sociales que considera organizan la sociedad, en este caso la política. Como veremos, los principales referentes de aquella organización poseían posiciones relativamente subordinadas en el espacio social y político y, por otro lado, se arrogaron la representación de sectores marginales que ocupaban esta misma posición, buscaron erigirse como representantes de los que estaban "afuera". Esta suerte de afinidad y/o convergencia de intereses fue moldeando atributos principales de lo que posteriormente sería el Frente para la Victoria. La coyuntura histórica en la que se situó el origen de esta organización fue clave en la conformación de su identidad, ya que a principios de la década de 1980 el campo político -tanto en Santa Cruz como a nivel nacional- estaba fuertemente atravesado por el discurso y las estrategias políticas para retornar a un sistema político democrático. Este escenario fue central en la construcción del Ateneo, esta fuerza política heredó concepciones políticas tanto de la izquierda como de la derecha peronista predominantes en la década de 1970, justamente las formas políticas que el discurso democrático de la época impugnaba y pretendía dejar atrás. El propósito de este trabajo es, en este sentido, establecer una línea de continuidad entre las primeras experiencias políticas de aquellos dirigentes en el Ateneo y sus concepciones políticas posteriores, especialmente el perfil militante de la organización.

\section{Los primeros pasos de los principales dirigentes del FVS en el Ateneo}

El Ateneo fue fundado en noviembre de 1981 por dirigentes asociados a la derecha peronista ${ }^{1}$ meses después de que el General Viola reemplazara a Videla en la presidencia de la Nación. Este grupo político estaba liderado por Nélida Cremona de Peralta, representante del peronismo "ortodoxo" en la Cámara de Diputados de 1973 y esposa de Hugo Peralta, Secretario General de la CGT local en ese mismo periodo y socio sindical de aquella línea política (Vilaboa y Bona, 2017). Este sector no sólo poseía posiciones de derecha en cuanto a las formas organizativas que debía adoptar el partido peronista, también mostraba ciertas cercanías con las posiciones más violentas contra la lucha armada, durante y después de la dictadura militar. Dentro del grupo fundador, participaron quienes impulsaron la intervención federal de la provincia de Santa Cruz durante el gobierno de Jorge Cepernic -vinculado a la Tendencia Peronista- entre 1973-1974, denunciado por su relación con Montoneros (Servetto, 2010). Los lazos con los sectores de la derecha peronista a nivel nacional fueron siempre considerados evidencias de los posicionamientos de este sector al interior del peronismo. Para el acto de lanzamiento de las listas en 1983 la organización invitó a Rodolfo Ponce, ícono de la Triple A en Bahía Blanca y en ese mismo encuentro realizaron un desagravio a este dirigente, quien fuera acusado por Alfonsín como parte del pacto militar-sindical. ${ }^{2}$

En 1982 se reestructuró la comisión directiva y Kirchner, posterior líder del Frente, se constituyó en vicepresidente de este nuevo lineamiento interno del peronismo de Santa Cruz que postuló a presidente del PJ provincial, en las internas del 
peronismo en 1983, a su tío Manuel López Lestón, un viejo militante peronista. ${ }^{3}$ Posteriormente, los fundadores, por lo menos sus principales referentes, migraron a las filas de la lista Celeste, un agrupamiento en el que convergió fuertemente parte del peronismo sindical y los sectores políticos peronistas más tradicionales que compitieron con la lista Verde, versión previa de la renovación peronista en Santa Cruz. Este primer quiebre muestra el inicio de la construcción política de Néstor Kirchner y presenta una particularidad: comienza a construir una organización por fuera de los grupos predominantes del peronismo asumiendo una relación distante y crítica de la organicidad típica de los agrupamientos y las estructuras políticas, en consonancia con sus primeros pasos en las prácticas de militancia en la ciudad de La Plata durante la década de 1970.

La fundación del Ateneo, su consolidación como tercer fuerza en la política de Santa Cruz, pese a su escasa proyección a nivel provincial, y su cooptación por parte de Kirchner, quien ejerció el liderazgo principal de la misma, constituye una de las evidencias más gráficas del carácter abierto y de la debilidad de las estructuras políticas en Santa Cruz, atributo de la política santacruceña que fue reconstruido y analizado por Sosa $(2014 ; 2016 ; 2017$ a), en aquella coyuntura. La estrategia de Kirchner para ascender en la política provincial fue acceder a la gobernación o a los niveles superiores de la política provincial directamente, sin pasar por ningún tipo de escalón político inferior que implique hacer una carrera política en una institución. Para 1983, Kirchner no tenía ninguna experiencia política local, había regresado recientemente de realizar sus estudios en La Plata, en los últimos años la política había sido suspendida por la dictadura militar, no pertenecía a los grupos sociales más prestigiosos de la provincia ${ }^{4} \mathrm{y}$, finalmente, era demasiado joven para ser gobernador, sólo tenía 33 años (Amato y Boyanovsky Bazán, 2008). Esta primera lectura de Néstor Kirchner sobre las relaciones políticas de la provincia es clave para comprender los rasgos del viejo Ateneo y la posterior política del FVS. Evidentemente, la debilidad de las estructuras políticas que Santa Cruz poseía, ya en 1983 y en consonancia con su historia política, expresada en la escasa cantidad de militancia, de habitantes, de cuadros políticos y de corrientes que nucleen dirigentes y militantes y conducciones políticas sólidas, como declaraba el mismo Kirchner cuando decidió regresar a Santa Cruz e iniciar su carrera política, mostraba el cargo de gobernador como una posición de fácil o rápido acceso. Como bien lo señalaba un entrevistado, "en Santa Cruz si tenés aspiraciones políticas en serio como mínimo querés ser gobernador. El poder está ahí al lado" (entrevista realizada por la autora).

\section{Los dirigentes del FVS y la militancia de los '70}

El Ateneo no sólo recibió influencias de los sectores de la derecha peronista. También recibió un fuerte afluente de sectores de izquierda, asociados a la militancia política de la década de 1970. Un grupo de dirigentes migrantes de la provincia de Córdoba que se fueron incorporando al Ateneo, había militado en la Vanguardia Comunista de esa provincia durante la etapa previa al golpe de Estado. Este grupo ingresó bajo el paraguas de Néstor Kirchner a la organización y la nutrió de un 
conjunto de cuadros, entre los que se encontraba Carlos Zannini, quien había estado preso durante la dictadura y quien cumplió un rol central en lo que sería posteriormente el FVS. Dentro de la que se denominó la "Banda de los cordobeses" muchos habían tenido una militancia activa y comprometida durante los años '70, incluso se interpreta que migraron hacia el sur buscando refugio ante los embates de la dictadura (Gatti, 2003).

Tanto Néstor Kirchner como Cristina Fernández de Kirchner, la segunda referente principal de lo que sería el FVS, también participaron de la militancia de los '70, pero lo hicieron en el marco del peronismo y tuvieron una relación distante, fugaz y crítica de las organizaciones de la militancia juvenil de esta fuerza política en La Plata, donde radicaban por aquel entonces. Néstor Kirchner había militado en la FURN (Federación Universitaria de la Revolución Nacional), organización que desde su nacimiento formó parte de la JUP (Juventud Peronista) y fue la herramienta que le permitió ingresar a la Universidad, un lugar que al peronismo le había estado vedado históricamente (Amato y Boyanovsky Bazán, 2008). Sin embargo, nunca formó parte de la conducción -siempre fue un adherente- $\mathrm{y}$, como veremos posteriormente, su tarea de militante fue sólo una corta participación orgánica en un grupo interno de la FURN denominado "púrpura" que constituía una de sus fuerzas de choque (Amato y Boyanovsky Bazán, 2008). Sin dejar de ser un militante y joven afectado por los hechos políticos, Kirchner participó activamente sólo hasta 1974, año en que las organizaciones de izquierda y armadas adoptaron una actitud distante con Perón. Las investigaciones periodísticas sobre su militancia muestran un Kirchner que, pese a encontrarse para su época activo políticamente, presentaba una distancia tanto con las jerarquías como con los modelos de militantes comprometidos de la época. El uso de la ironía y del humor en el trato con sus compañeros como con sus jefes -que siempre lo caracterizó- expresaba un desdén por estas organizaciones (Wornat, 2005; Amato y Boyanovsky Bazán, 2008). Pese a esto, Kirchner, aunque nunca rompió, se mantuvo al margen de lo que se comenzó a hacer táctica y estratégicamente en las organizaciones vinculadas a Montoneros. La nueva relación con Perón, la lucha armada, la violencia creciente y el aislamiento de las organizaciones de la sociedad, lo llevó a retirarse gradualmente, con un grupo de compañeros, de la militancia más comprometida (Wornat, 2005; Russo, 2013).

Pese a ciertas diferencias, la trayectoria de militancia de Cristina Fernández de Kirchner tuvo en común con la del principal referente del FVS una postura distante y poco integrada a la intensidad de la participación que poseía la política de la época. Tuvo un breve acercamiento al Frente de Agrupaciones Eva Perón (Organización Universitaria ligada a las FAR) y en 1973 comenzó a participar por muy corto tiempo en la JUP (Wornat, 2005). Lejos de presentar una participación orgánica, menor aún que la de Kirchner, su participación en los actos más significativos de la época fueron realizados de manera individual por fuera de las clásicas movilizaciones organizadas a través de las estructuras juveniles de la época. Esta actitud distante de las jerarquías y de las formas de organización orgánicas y verticales se muestra en las investigaciones periodísticas actuales 
sobre su personalidad y su desempeño público, en los que se resaltan su actitud confrontadora, cuestionadora y poco proclive a la obediencia partidaria (Wornat, 2005; Russo, 2013). Probablemente, la escasa pertenencia orgánica a la JUP haya influido en las razones que la distanciaron de la militancia más activa de los '70. Como ella misma lo ha señalado, nunca estuvo de acuerdo con desconocer a Perón como el líder natural del proceso de cambio en la Argentina (entrevista a Cristina Fernández de Kirchner en el Canal Público, 2011; Russo, 2013). Esta distancia con las dirigencias juveniles tenía como contracara, especialmente en Cristina Kirchner, una fuerte adhesión a la figura de Perón. Su madre, Ofelia Whilem, era una devota tanto de Perón como de Evita y ejerció, según relata la misma Cristina Fernández, una fuerte influencia en el reconocimiento que tuvo de manera directa con estas figuras políticas. Según sus propias declaraciones, el acto político más significativo de la historia de la época en el que participó fue el trunco acto de bienvenida de Perón después de 18 años de exilio, conocido como la masacre de Ezeiza, al que asistió para acompañar a su madre (entrevista a Cristina Fernández de Kirchner en el Canal Público, 2011; Russo, 2013).

Según relatan las biografías, investigaciones periodísticas y las entrevistas realizadas para esta investigación (Wornat, 2005; Amato y Boyanovsky Bazán, 2008; Russo, 2013), paralelamente al distanciamiento de la actividad política y el inicio del letargo político que implicó el comienzo de la dictadura militar en 1976, para el matrimonio Kirchner comenzaba una nueva historia. Los Kirchner se casaron en mayo de 1975 y el mismo año, en una visita a Río Gallegos, fueron presos en esa ciudad, en enero de 1976. No existe consenso sobre la cantidad de días que permanecieron detenidos. Las disímiles versiones de los protagonistas así como también de los documentos periodísticos que reconstruyen su trayectoria no permiten una única lectura. Algunas interpretaciones sostienen que permanecieron presos 28 días en la cárcel por sus antecedentes políticos mientras que otras señalan que fueron sólo algunos días. Sin embargo, todas las versiones coinciden en que no fueron sometidos a malos tratos. Probablemente por esta razón, de vuelta en La Plata decidieron regresar a esa ciudad; pese a su experiencia, Santa Cruz seguía siendo un lugar seguro para resguardarse de la persecución y la violencia política que en los últimos años de sus estudios en La Plata se había exacerbado. Sin embargo, el matrimonio decidió postergar su mudanza a la Patagonia hasta que Kirchner concluyó sus estudios de abogacía, en julio de 1976. Como ha sido señalado por las fuentes que abordan su experiencia en esta etapa, el principal dirigente del FVS quería terminar su carrera universitaria antes de partir, aún pese a los riesgos crecientes que presentaba el aumento de la violencia política, para hacerse una posición en la provincia, condición para comenzar su carrera política hacia la gobernación de Santa Cruz (Wornat, 2005; Amato y Boyanovsky Bazán, 2008).

\section{La elección de un "grupo de referencia" y sus consecuencias para la organización}

Como consecuencia de las estrategias políticas de Néstor Kirchner basadas en esta lectura del escenario político y la carencia de capital político colectivo que su- 
ponía el nuevo Ateneo (este agrupamiento era de creación reciente), se fue formateando esta organización. La primera estrategia, y quizás una de las más importantes, fue pretender representar a sectores sociales no reconocidos por los partidos políticos en general y al PJ en particular que ocupaban posiciones marginales en el espacio social de la provincia y no constituían grupos de referencia de los mismos. La primera y más representativa Unidad Básica (UB) del Ateneo, denominada "Los muchachos Peronistas", fue la segunda UB fundada en Río Gallegos hacia marzo de 1976 y se ubicó en el Barrio Nuestra Señora del Carmen, una importante y humilde barriada, donde se asentaban mayoritariamente quienes llegaban a la ciudad principalmente desde Chile o de otras provincias del país en busca de ocupaciones en la administración pública o en tareas de construcción (Gatti, 2003; Garrone y Rocha, 2003). Fernando Ulloa Igor, el jefe de la militancia de base del FVS, pertenecía al barrio del Carmen y fue el nexo principal entre Kirchner, en tanto principal referente del Ateneo, y este sector particular de la ciudad de Río Gallegos. Algunos relatos muestran cómo aquella organización, era asociada con estos sectores y la importancia que tuvieron para esta fuerza política:

Kirchner es un outsider. Intentó por adentro, fue a internas con Puriccelli, etc. etc., la política era así antes. Si vos tenías aspiraciones políticas, mínimo quiero ser gobernador. Y después, siendo candidato digo...quiero llevar a este intendente, aquel otro y aquel otro, para que me acompañe. El Lupo fue al revés. Así no puedo...entonces fue por la intendencia. Era totalmente antiestético. Fumador, siempre fumando. Mal vestido, de mala presencia, etc. Fue en contra de todos los pronósticos. ¿Qué hizo? Se apoyó en los sectores del otro lado de Santiago, a donde está la chilotada, los chilotes. Ni peronistas, ni radicales. Y él armó con ellos porque nadie se metía con la chilotada ${ }^{5}$ (Ex militante del FVS. Entrevista realizada por la autora, noviembre de 2009).

La elección de estos sectores sociales le imprimió un perfil de base muy fuerte al Ateneo que, en defensa de las mismas, cargó fuertemente contra toda la dirigencia política de la provincia. En nombre de la defensa de los sectores más marginales el Ateneo se identificó como el peronismo puro, entendido como aquel que defiende los verdaderos intereses del pueblo, y estableció una oposición directa a las burocracias partidarias del peronismo, a las que leyó como representantes de sus propios intereses. En consecuencia, la defensa a ultranza de las bases redundó en el desconocimiento y la crítica del resto de los lineamientos internos del PJ provincial. Así lo expresaba Néstor Kirchner en las internas de 1983 en un acto del Ateneo Juan Domingo Perón:

\section{Compañeros:}

Hoy, llegamos a este plenario convencidos de que somos los depositarios de la moral justicialista en el peronismo de la provincia de Santa Cruz. Nosotros, que si bien nos duele que en el peronismo de Santa Cruz haya tres listas para las internas también nos llena de orgullo ser la única opción peronista donde no hubo acuerdos espurios, roscas y ne- 
gocios políticos. Cuando nacimos, un lejano 28 de noviembre de 1981 dijimos, compañeros, a lo largo y a lo ancho de todo Santa Cruz que aquellos que estuvieron antes y nada hicieron no van a volver nunca más porque le vamos a oponer nuestra conciencia y nuestro pecho peronista para que eso no suceda más compañeros.

Nosotros...donde hay un pueblo que está pasando hambre, donde hay desocupados, donde la represión de la dictadura militar han ensangrentado todo el pueblo argentino nos parece vergonzante que haya campañas multimillonarias en el peronismo, donde dicen que van a defender al pueblo, mientras ese pueblo está sumergido en la última de las miserias, compañeros.

Bombos, Lupín, Lupín, Lupín. Si este no es el pueblo, el pueblo donde está.

Aquellos, que creen que pegando carteles, que parecen esos carteles de las películas far west, de las películas norteamericanas, nosotros les decimos que como el 24 de noviembre de 1946 los negritos y los grasitas que estamos agrupados en el Ateneo les vamos a ganar las internas con la tiza y el carbón compañeros.

Somos los negros, somos los grasitas, somos la gente que vino con Evita (repite).

(Discurso de Néstor Kirchner en el Ateneo Juan Domingo Perón en 1983. Archivo General de Alejandro Cappa).

La crítica a las dirigencias políticas no iba solo dirigida a aquellos que ocupaban posiciones "de prestigio" en el interior del PJ, sino también a cualquier tipo de organización burocrática que separe "el pueblo" de sus "verdaderos representantes", reivindicando de esta manera y de manera indirecta una organización sin mediaciones. El debate interno del PJ en 1983 entre verticalistas y antiverticalistas permite visualizar el perfil de organización que reivindicaba el Ateneo y un conjunto de acciones que se derivaban de ella. Mientras el líder de Herencia y Mandato, un lineamiento interno del PJ tradicional de la provincia, manifestaba que "El dedo de Isabel Perón no puede ser cuestionado por nadie" (Felipe Ludueña, Correo del Sur, 27/07/1983) y defendía la centralidad de las ramas sindical, política y femenina en el congreso peronista, los asociados con el antiverticalismo reivindicaban el rol de sus afiliados. En este escenario, el Ateneo, en su lucha con los sectores tradicionales del PJ asumía una posición ultraverticalista. Reivindicaba el alineamiento extremo a Isabel Perón negando cualquier mediación burocrática, en ese entonces representado en el congreso peronista, que imposibilite la representación directa del "pueblo". En ocasión de una visita de Ítalo Luder -uno de los principales dirigentes del PJ a nivel nacional- a Río Gallegos, el Ateneo irrumpió en un acto partidario entonando el cántico "Isabel conducción lo demás es traición" (Gatti, 2003: 17; Vilaboa y Bona, 2017) haciendo gala de una idea de organización fuertemente verticalista y delegativa. De este suceso puede leerse el tipo de organización que reivindicaba para sí el Ateneo, una organización que no posea mediaciones 
políticas, es decir, mecanismos de selección de representantes, de competencia interna, de reglas que regulen la competencia en el interior del colectivo político. Reivindicaba para las organizaciones, y eso claramente influyó en el gran poder de decisión que tuvo Kirchner en esa pequeña organización, un vínculo directo entre el líder y las bases. Cualquier aparato de mediación burocrática entre "el pueblo" y "los líderes" significaba, necesariamente, una defensa de intereses corporativos.

\section{Las concepciones sobre la organización y el liderazgo interno de Néstor Kirchner}

Como se ha podido observar en el apartado anterior, la elección de un "grupo de referencia" fuertemente marginal como estrategia de posicionamiento del Ateneo en el sub campo del PJ y las aspiraciones políticas de ascenso de un dirigente con escaso capital político y social redundaron, como producto de una relación de homología de intereses (Bourdieu, 1984), en un posicionamiento político anti dirigencia, acompañado de la denuncia de cualquier tipo de mediación organizacional como un tipo de defensa de intereses espurios y corporativos. La convergencia entre la defensa de un grupo marginal de la sociedad y las pretensiones políticas de referentes subordinados en el espacio político, produjo, como ya se ha señalado, una concepción de la organización fuertemente centralizada. En este apartado nos ocuparemos de describir otros atributos que se desprendieron de esta relación de homología: las formas de acción típicas del Ateneo, los fundamentos del liderazgo interno de Néstor Kirchner y la ideología de la organización.

El Ateneo se caracterizó, reiteramos, en el concierto del peronismo de la época por su capacidad de movilización e impronta militante. La política en Santa Cruz, en esa coyuntura, no se caracterizaba por su poder de movilización y el Ateneo expresaba un contraste en ese sentido. Sin embargo, su participación en el espacio público no se limitaba sólo a movilizar, también se caracterizaba por irrumpir en actos partidarios con una impronta disruptiva siempre en busca de cuestionar la legitimidad de una dirigencia a quien acusaba de no ser representativa de las bases. El Ateneo era caracterizado, por este atributo, como el peronismo "duro" y "combativo". ${ }^{6}$ El uso de metodologías confrontativas con las propias líneas internas del peronismo, entre las que se encontraban las concepciones de "ganar la calle", implicó que fueran considerados por ciertos sectores como una fuerza que "está en el enfrentamiento y la destrucción", especialmente frente a las pretensiones de unidad que reivindicaban todos los sectores del peronismo en 1983. ${ }^{7}$ De estas formas de comportamiento se desprendían alusiones a Kirchner, de parte de los dirigentes con más trayectoria, como el "zurdo" o el "montonero" (entrevistas realizadas por la autora). La crítica a la dirigencia iba acompañada, en consecuencia, por una acción de irrupción en el espacio público en el que se hacían visibles las bases y simultáneamente se desconocía la dirigencia política. Los chilenos y los recién llegados no sólo no votaban en las elecciones (salvo para las comunales) y, en este sentido, no eran los sectores más atractivos para los partidos desde el punto de electoral. Poseían fuertes déficits de integración a la comunidad, situación que se combinaba con posiciones subordinadas en el comunitario espacio social local. 
En este marco, la crítica a la dirigencia iba acompañada por una acción política de movilización e irrupción en el espacio público que tenía como objetivo hacer visibles a los invisibles.

Si el carácter invisible de los sectores que buscaba representar el Ateneo explica las condiciones de posibilidad de la acción vinculada a la irrupción física en el espacio público, la trayectoria política de Néstor Kirchner y la construcción de liderazgo en el interior de la organización explica el carácter confrontativo y disruptivo de estas apariciones públicas. Efectivamente, la idea de tomar las calles y poner el cuerpo como método principal de participación en el espacio público, no sólo tuvo que ver con la impronta basista y militante de esta nueva organización y la pretensión de poner el "verdadero pueblo" en la calle; también la trayectoria política pasada del principal líder del Ateneo influyó fuertemente en el perfil de la misma. Como hemos señalado, en su experiencia política en La Plata, Néstor Kirchner, no había formado parte de la dirigencia, tampoco se había caracterizado por sus dotes de orador, destreza política por la que, según califican sus contemporáneos, nunca se destacó. Contrariamente, si bien poseía una actitud cuestionadora ante los planteos de los dirigentes, se destacó como militante por su capacidad de "poner el cuerpo". Las investigaciones sobre su participación como militante en los "70 lo muestran ocupando funciones asociadas a la defensa de la integridad física de los participantes de la organización y la resolución de conflictos políticos a través de la fuerza física. ${ }^{8}$ Así lo señalaban en una entrevista los autores de "setentistas", biografía sobre la militancia en los '70 de Néstor Kirchner:

Néstor Kirchner se integró a la Federación en el año 71. Era un joven que llamaba la atención por su metro 87 de estatura, característica que le valió integrar la Banda Púrpura, una suerte de grupo de choque de la FURN. En ese marco el santacruceño no es recordado por su oratoria -si bien se destacaba en las discusiones en los claustros universitarios-, tanto como por su disposición a "ir al frente" (Revista 2016, N${ }^{\circ} 15$, Marzo de 2008).

Buena parte de la legitimidad y el carisma de Néstor Kirchner en el interior de la organización se basó en encarnar, en los actos políticos de la agrupación, el papel de un militante que se destacaba por su capacidad de "ir al frente". La siguiente entrevista muestra cómo se expresaba este liderazgo y la diferencia que implicaba con relación al resto de los sectores políticos del PJ:

En 1982 se arma una plaza en defensa de la apertura democrática. Acá en Roca y San Martín. Vinieron referentes de todas las fuerzas políticas. Toda la casta política tradicional de la provincia. Todos tranquilos. Ningún orador. Poca gente en la esquina. De pronto, un acto pacífico con poca concurrencia, se sienten los bombos...ta, ta, ta y aparece una banda de gente marchando por San Martín y el Lupo a la cabeza, fumando el tipo, viene a la esquina. Llega y dice: compañeros...Vamos a defender la democracia! Y encara por Roca a la casa de gobierno y todos fuimos atrás. No te podías quedar y no marchar...llegamos a la 
casa de gobierno. Vino la tele, la policía, etc. y el tipo lideró el asunto. Hacía cosas así (Ex militante del FVS. Entrevista realizada por la autora, noviembre de 2009).

La fuente del liderazgo de Néstor Kirchner en el interior de la organización se basó en su capacidad de encarnar los valores de la igualdad de jerarquías. El tipo de liderazgo que encarnó se asentó en la representación de los valores de una organización que se decía representativa de las bases. Kirchner se ubicó así en el rol de un militante más hasta el punto de asumir el lugar de fuerza de choque, la tarea de menor jerarquía en una organización, otorgándole un sentido igualitario que cumplió un papel central en la consolidación del liderazgo interno de Kirchner. Esta idea de igualdad constituyó uno de los pilares fundamentales de la organización del Ateneo, y como veremos posteriormente, del FVS. De manera paradójica Kirchner fue el más distante de los miembros de la organización para tomar las decisiones, ya que desde los inicios no se subordinó a ninguna estructura formal o informal que implicara algún tipo de delegación de poder y, paralelamente, el más cercano a los mismos en cuanto a su compromiso y su trabajo de base. Buscó siempre, en esta primera etapa pero también en su trayectoria como líder del FVS, ubicarse con sus acciones, no así con sus decisiones, cercano a sus representados.

Ahora bien, como ha señalado Panebianco (1990: 17), los resultados de las primeras jugadas, las opciones políticas cruciales puestas en práctica por los padres fundadores, las modalidades de los primeros conflictos por su control y la manera en que éstas se consolidan, dejan una impronta indeleble en las organizaciones políticas. Partiendo de este supuesto y retomando los interrogantes iniciales de este artículo vale preguntarse ¿cómo influyó la experiencia del Ateneo en la conformación del Frente para la Victoria y en su perfil político? ¿En qué medida y de qué forma la experiencia del Ateneo le permitió al Frente para la Victoria sortear positivamente contextos de incertidumbre social y política, tipos de contextos en los que se desarrolló esta fuerza política? ¿Por qué es posible sostener que fue esta experiencia la que dotó al Frente para la Victoria de un conjunto de concepciones políticas que le permitieron desenvolverse en contextos de incertidumbre y crisis política? De otra manera, ¿qué es lo que persistió del Ateneo en el FVS y el FPV? En los apartados siguientes abordaremos estos interrogantes.

\section{Primera herencia del Ateneo: la reducción de las mediaciones}

En primer lugar, lo que puede observarse como herencia del Ateneo es la voluntad política de su principal dirigente, Néstor Kirchner, de liderar la fuerza y no subordinarse ninguna estructura política o mecanismo de sucesión que implique acuerdos con otras fuerzas para llegar al poder. Este rasgo, aunque podría ser interpretado como un atributo "natural" de cualquier líder, es clave para comprender la conformación y el perfil del Frente para la Victoria.

Esta continuidad se hace visible en la trayectoria política y las decisiones de este dirigente durante la década de 1980. En 1983, Kirchner fue nombrado por el entonces gobernador electo Arturo Puriccelli como Presidente de la Caja de 
Previsión Social de la provincia de Santa Cruz, cargo al que renunció en 1984 por las limitaciones que sufrió a los intentos de armar una base política propia (autónoma del partido) (Gatti, 2002; Garrone y Rocha, 2003; Sosa, 2014; Vilaboa y Bona, 2017). En 1986 fracasó en un acuerdo con los dirigentes del Movimiento Renovador Peronista a través del cual pretendía ser el candidato a la gobernación por el PJ en las elecciones de 1987. Como consecuencia, ese mismo año, frente a la imposibilidad de ir "por dentro" de los acuerdos y alianzas usuales en el partido para acceder a la gobernación, decidió comenzar a armar un capital político propio desde la intendencia de Río Gallegos, ciudad en la que se había fundado el Ateneo y en el que concentraba su mayor capital político (Gatti, 2003; Garrone y Rocha, 2003; Sosa, 2014; Vilaboa y Bona, 2017). Este viraje fue clave: en 1991 Kirchner llegó a la gobernación gracias a su paso por la intendencia de aquella ciudad desde donde construyó y comenzó a desplegar sus redes a nivel provincial luego de fundar, en 1989, el Frente para la Victoria. Esta pretensión de ejercer un liderazgo autónomo lo llevó a cambiar su estrategia de construcción política, optando por una alternativa más distante de las mediaciones partidarias y reproduciendo el perfil marginal fundado en el Ateneo.

Una trayectoria similar puede encontrarse en la instancia de construcción de su liderazgo a nivel nacional. Pese a que Néstor Kirchner llegó en el año 2003 a la presidencia, gracias a un acuerdo personal con Eduardo Duhalde (entonces presidente de la Nación), su postulación no fue producto de un acuerdo entre las corrientes internas del partido peronista; por aquellos años esa organización se presentó dividida y postuló a tres candidatos. El acuerdo con Duhalde, por otro lado, tuvo fuertes componentes aleatorios. Como ha sido reconstruido por las crónicas periodísticas de la época, la elección de Kirchner como candidato por parte de Duhalde fue improvisada, coyuntural y fuertemente azarosa (Garrone y Rocha: 119-135). El perfil de liderazgo autónomo, ejercido a nivel provincial en Santa Cruz, no tardó en ponerse en juego. Dos años después, en 2005, Néstor Kirchner postuló a su esposa, Cristina Fernández de Kirchner como su candidata a Senadora Nacional en la provincia de Buenos Aires, quien compitió por el cargo con "Chiche" Duhalde, la esposa de Duhalde, quien había gobernado la provincia entre 1988 y 1999 (Calvo, 2005). Por aquellos años, la idea de que la provincia de Buenos Aires, y especialmente el Conurbano, estaba completamente monopolizada por el gobernador era incuestionable, existía una fuerte representación de un poder invencible. ${ }^{9}$ De ahí la osadía de Néstor Kirchner de, no sólo disputarle el poder a quien le había ofertado el cargo de presidente, sino también de dar la batalla política contra el dirigente que dominaba desde la década de 1980 el distrito electoral más grande del país. Atrás quedaron, en solo dos años, las representaciones de que Kirchner era "el chirolita de Duhalde" (Dagatti, 2013); la idea de liderazgo autónomo que ya se expresaba en el Ateneo y luego en el FVS volvió nuevamente a guiar sus acciones políticas. Néstor Kirchner no se iba a subordinar a ningún acuerdo político que condicione su acción; la lealtad era, en principio, al tipo de liderazgo y tipo de poder que quería ejercer, con ciertas distancias y en tensión con lo que se consideraban las mediaciones partidarias. 
En segundo lugar, lo que puede observarse como continuidad entre el perfil del Ateneo y el Frente para la Victoria en sus dos escalas, nacional y provincial, es el esquema de toma de decisiones. La negación de las mediaciones internas para elegir candidatos, seleccionar representantes, competir internamente y representar a los electores que asumió el Ateneo a principios de la década de 1980 le imprimió a la organización del FVS un perfil personalista, concentrado y vertical. Como hemos mostrado, las influencias de los grupos de la ultra derecha peronista que formaron parte del Ateneo y la negación de las formas burocráticas partidarias de representación y competencia interna le imprimieron a esta organización un fuerte carácter movimientista que, en pos de la representación directa de las mayorías, defendía una posición ultraverticalista como modelo de toma de decisiones.

Este esquema de toma de decisiones se replicó tanto en la experiencia provincial como nacional. En Santa Cruz, Néstor Kirchner ejerció un liderazgo fuertemente concentrado en cuanto a la toma de decisiones y extremadamente radial, rasgo que se potenció por la ausencia de relaciones horizontales entre sus miembros y el carácter atomizado de la organización y también de su gobierno (Sosa, 2014). Pese a la tradición personalista que el PJ tenía, tanto a nivel provincial como nacional, el FVS llevó este rasgo al extremo. Sólo a modo de ejemplo, esta organización eliminó, a través del gobierno del consejo partidario local la representación de las minorías en el partido y, por otro lado, creó un fondo económico denominado "Aportes voluntarios al Frente para la Victoria" para sortear el control de los fondos aportados por los dirigentes que accedían a bancas en representación del partido (Sosa, 2014). Su trayectoria como gobernador y las estrategias para mantenerse en el poder también hacen visible los niveles de concentración de poder político -y como consecuencia de toma de decisiones- que tuvo su gobierno. Esta organización no sólo gobernó la provincia en tres periodos consecutivos sino que llamó a elecciones para reformar la constitución de la provincia en 1994 y 1999 para cambiar las cláusulas que prohibían la reelección (Sosa, 2014, 2017a; Vilaboa y Hudson, 2016).

Aunque es difícil identificar de manera sistemática si los niveles de concentración de toma de decisiones fueron similares a estos es la escala nacional, existen estudios que han señalado que el FPV acentuó la matriz delegacionista. Como hemos detallado a principios de este artículo, los estudios sobre el FPV en su experiencia nacional también han señalado el perfil plebiscitario, delegativo y asentado en el apoyo y la representación de las mayorías que ha tenido esta fuerza política a nivel nacional. Especialmente los estudios desarrollados desde la Ciencia Política sostienen que el FPV acentuó el diseño institucional de presidencialismo fuerte aplicado en los gobiernos de Carlos Menem, esquema que concentró el poder político en el Ejecutivo en detrimento del resto de los poderes del Estado, acentuando la tendencia delegativa del poder político en la Argentina (Serrafero, 2011; De Luca, 2011; Gargarella, 2011; Gervasoni, 2011; Levitsky y Murillo, 2008). ${ }^{10}$ 


\section{Segunda herencia del Ateneo: El perfil militante de la organiza- ción}

El perfil del liderazgo de Néstor Kirchner, su pretensión de construir una carrera política autónoma de las estructuras partidarias, y el esquema concentrado de toma de decisiones han sido atributos forjados en la experiencia del Ateneo. Sin embargo, estas formas -aunque en menor nivel de concentración en el periodo democrático argentino- han estado presentes en la política argentina en general y en el peronismo en particular. Existe un consenso reflejado en los estudios sociales argentinos antes citados en que el personalismo, el presidencialismo, los liderazgos fuertes -en detrimento de los partidos-, el carácter delegacionista y mayoritario de los regímenes democráticos o el bajo republicanismo es un rasgo de la política nacional. En ese sentido, el Frente para la Victoria tendría de particular, en función de los datos y las interpretaciones que hemos citado con anterioridad, haber llevado al extremo esa lógica; su especificidad estaría dada sólo por una cuestión de grado. Es decir, lo que definiría a esta fuerza sería su personalismo acentuado, su mayor verticalismo y su mayor concentración de poder.

Es el carácter militante del Frente para la Victoria el atributo que quizás mejor defina la especificidad, identidad o particularidad política que caracterizó a esta organización en la escala provincial y nacional y que, como hemos visto en los apartados anteriores, tuvo origen en la experiencia del Ateneo. Las concepciones de tomar la calle, de poner el cuerpo, de comprometerse en la política, de ir al frente, la reivindicación de igualdad entre representantes y representados y la disciplina interna, características que definían al Ateneo como el "peronismo duro y combativo" siguieron siendo el sello que identificó al Frente para la Victoria. A nivel provincial, el perfil militante fue lo que diferenció al FVS del resto de las corrientes políticas, especialmente del peronismo. La idea de trabajo permanente y entrega total, renuncia, tolerancia a la adversidad y compromiso, fueron máximas de la organización que encarnaron tanto los líderes, los dirigentes y los militantes de la organización independientemente de su posición en las jerarquías internas de la fuerza (Sosa, 2014, 2017b). ${ }^{11}$

El origen social de los dirigentes que confluyeron en el Ateneo, su posición política y social subordinada -en la provincia de Santa Cruz- y la pretensión de representar a los sectores subordinados de la política local, acentuó y reprodujo en los dirigentes que comenzaron su trayectoria política en la vieja organización las matrices políticas aprehendidas en la década de 1970 y durante la dictadura militar. Tanto los dirigentes que habían comulgado con las ideas de la dictadura militar o de la derecha peronista, como aquellos que provenían de organizaciones de izquierda peronista y no peronista estaban socializados en organizaciones políticas en las que el compromiso y la disciplina eran máximas centrales.

Este perfil militante ha influido en múltiples dimensiones de las relaciones políticas en la experiencia nacional del FPV, con distintas variantes. Efectivamente, la explosión de estudios vinculados a "la militancia" en los últimos años -que tienen como objeto al kirchnerismo en sus diversas facetas- es quizás el indicador más significativo de la centralidad de este atributo en la definición de la identidad de 
esta fuerza política. ${ }^{12}$ Una primera línea de estudios se ha ocupado de esta temática como una forma de activismo, especialmente a partir del aumento de la participación de los jóvenes en la política, la construcción de esta categoría social como un grupo de referencia, cantera de reclutamiento y categoría interna de los partidos (Vázquez y Vommaro, 2012; Vázquez, 2013). Partiendo de interrogantes clásicos que buscan desentrañar la relación de las organizaciones partidarias con el Estado, otra línea de estudios analizó la relación de "los militantes" con esta institución, a partir del análisis de los cargos ocupados, el despliegue de sus concepciones políticas en el interior y sus formas de habitarla (Perelmiter, 2010; Novaro, 2011; Rocca Rivarola, 2014, 2016; Perez y Natalucci, 2012). Una tercera corriente investigó "la militancia" en el discurso político de los líderes del Frente para la Victoria (FPV), Néstor Kirchner (Presidente de la Nación, 2003-2007) y Cristina Fernández de Kirchner (Presidenta de la Nación, 2007-2015), analizando cómo la presentación de sí de los principales conductores de la organización fue una forma de representar a la sociedad y construir carisma (Montero, 2007, 2012; Novaro, 2011; Sosa, 2014, 2017b). ${ }^{13}$ Finalmente, el análisis del perfil militante formó parte del estudio de los movimientos sociales kirchneristas y no kirchneristas (Perez y Natalucci, 2012; Vazquez y Vommaro, 2012), del perfil cultural de esta organización (Novaro, 2011) y de las elites políticas (Sosa, 2017b). La abundante bibliografía sobre las distintas dimensiones de existencia política del FPV puede tomarse como una evidencia de las influencias que ha tenido el perfil fundado en el Ateneo en la experiencia política del FPV a nivel nacional. Queda pendiente profundizar sobre estas continuidades y sobre las particularidades que fue adquiriendo este perfil, así como también sobre cómo se puso en juego en cada momento político, en las distintas escalas y en interrelación con diversos, heterogéneos y distintos actores políticos.

\section{Palabras finales}

La trayectoria del Frente para la Victoria en la provincia de Santa Cruz presenta curiosos parecidos con el recorrido de esta fuerza política a nivel nacional desde 2003 hasta la actualidad: profundas crisis sociales como telón de fondo de su ascenso político, un escaso capital de legitimidad propia para acceder a los niveles superiores de la jerarquía política y una fortaleza indiscutida para ganar sucesivas batallas electorales. Tanto a nivel nacional como provincial, el FPV logró "superar" la crisis, incrementar los niveles de legitimidad y, simultáneamente, consolidarse en el poder por sucesivos periodos de tiempo.

En este trabajo se reconstruyó el origen de un conjunto de atributos, forjados en la experiencia del Ateneo en la provincia de Santa Cruz a principios de la década de 1980, que dieron forma a un conjunto de concepciones y formas organizativas del Frente para la Victoria, tanto a nivel provincial como nacional. Estos atributos nos brindan algunas claves interpretativas para poder comprender la capacidad del Frente para la Victoria para transitar periodos de crisis social y política. Puede considerarse que el tipo de liderazgo "autónomo" que Néstor Kirchner pretendió ejercer, alejado de las estructuras, tradiciones y las media- 
ciones partidarias, el carácter concentrado y vertical del ejercicio de poder en materia de toma de decisiones y el perfil militante de la organización, conforman características de aquella fuerza política que le permitieron transitar y constituirse en una fuerza política dominante en esos escenarios. En un contexto en que las estructuras políticas estaban en crisis, tanto a nivel provincial como nacional, esta organización se presentaba con una fortaleza y una certeza que resultaba atípica y distante de la incertidumbre generalizada que existía en Santa Cruz hacia fines de la década de 1980 y en la Argentina en el contexto de 2001. Más allá del perfil ideológico que el Frente para la Victoria tuvo en su experiencia provincial, más ligado -aunque con sus matices-a las políticas neoliberales de la década de 1990, y en su experiencia nacional, presentándose como una superación de ellas, esta organización mantuvo un conjunto de rasgos en toda su trayectoria que definieron en cierta medida su identidad. Su descripción permite aproximarnos a una lectura menos contingente de sus acciones políticas y reflexionar sobre lo que ha sido permanente en esta fuerza política, más allá de sus posiciones ideológicas coyunturales.

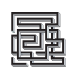

\section{Referencias}

1. Véase "Nueva asociación civil. Fue fundado el Ateneo Juan Domingo Perón" (La Opinión Austral, 29/11/1981).

2. Citado en Vilaboa y Bona (2017). Extraído de La Opinión, Santa Cruz, 24 de abril y 15 de mayo de 1983. De ese acto participaron Alicia y Néstor Kirchner, Cristina Fernández y Armando Mercado, esposo de Alicia Kirchner y secretario general del SUPE de Río Gallegos quien poseía lazos fluidos con Diego Ibáñez, también ligado a la derecha peronista. A propósito puede consultarse Gatti (2003) y "Derechos Humanos, la bandera que no podía mancharse" por Laura Di Marco (La Nación, 01/03/13).

3. Véase "Ateneo Juan D. Perón: Quedó constituida su nueva Comisión Directiva" (La Opinión Austral, 11/08/1982).

4. Néstor Kirchner provenía de una clase media trabajadora. Su padre, Carlos Kirchner repartía su día entre su principal trabajo, como empleado de correos -en el que realizaba tareas de contabilidad-, hacía tareas de mecánico dental en un pequeño taller en el fondo de su casa y vendía entradas por la noche los días de función en el cine de Río Gallegos. Paralelamente llevaba la contabilidad de pequeños clientes entre los que estaban algunos comercios del pueblo. Carlos Kirchner padre era hijo de pioneros y una persona muy reconocida en la pequeña comunidad. Se lo recuerda como una persona muy querida, trabajadora e incansable, austera, de escasa vida social y con cierta inocencia (Garrone y Rocha, 2003, pp. 33-44; entrevistas realizadas por la autora). Su madre, nacida en Chile, se había conocido con el padre aun estando en su país y se radicó en la Argentina para casarse con Carlos Kirchner padre y también fue empleada del correo en Río Gallegos. No tuvieron una vida económica holgada (Garrone y Rocha, 2003, pp. 33-44; entrevistas realizadas por la autora). Néstor Kirchner y su hermana, Alicia Kirchner, realizaron sus estudios universitarios financiados en parte por becas otorgadas para estudiantes por el gobierno de Santa Cruz. Néstor Kirchner estuvo a punto de suspender sus estudios en 1971 porque su hermana Alicia no había terminado su carrera de Trabajo Social y el gobierno provincial sólo financiaba a un miembro por familia (Amato y Boyanovsky Bazán, 2008). Según han señalado algunos entrevistados, Néstor Kirchner recibió colaboración de familias amigas para finalizar sus estudios y Alicia Kirchner recibió ayuda económica de sus amistades en los primeros tiempos luego de radicarse nuevamente en Santa Cruz (entrevistas realizadas por la autora). Todo indica que la familia tuvo serias dificultades económicas para sostener los estudios universitarios de sus hijos. Los miembros principales del FVS comparten este perfil social de clase media trabajadora.

5. Chilotes son aquellos chilenos que vienen de una isla de Chile llamada Chiloé. Sin embargo, en 
Santa Cruz y otras provincias de la Patagonia con migración chilena, chilote es utilizado como un adjetivo personal despectivo.

6. Revista Tesis, Año 1, abril de 1983 .

7. Véase "Panorama Político Semanal" (La Opinión Austral, 15/08/1982).

8. Revista 2016, "Los Kirchner: de la FURN a la Rosada", $N^{\circ} 15$, marzo de 2008. Disponible en http://www.revista2016.com.ar/entrevistas/-Los-Kirchner--de-la-FURN-a-la-Rosada.php [2013].

9. Véase "El corleonismo", por Juan Pablo Feinmann (Página 12, 13/05/07).

10. En una comparación sobre las formas de ejercicio de poder y toma de decisiones en el interior del gabinete ministerial que compara los sucesivos gobiernos nacionales desde 1983 hasta 2003, peronistas y radicales, De Luca (2003) ha mostrado cómo Néstor Kirchner ha sido el presidente que más concentró la toma de decisiones.

11. Como ha sido mostrado en Sosa (2014), en esa etapa de su trayectoria política, "ser militante" expresó la pretensión de representación de un atributo cultural de aquel territorio: "la cultura del sufrimiento". Esta matriz cultural, originada y expresada en el espíritu y en el discurso de los "pioneros" y las instituciones militares -grupos dominantes de la política local-, fue un valor diferenciador de la sociedad santacruceña e influyó fuertemente en las acciones y en la obediencia interna del grupo de los mandatarios del FVS. Especialmente en los que habían arribado a la misma recientemente, trayectoria migratoria que predominaba en las filas del grupo dirigente de aquella organización (Sosa, 2014, 2017b). El carácter militante expresó, en este sentido, una estrategia de representación de los miembros de la elite que tuvo fuertes impactos en la forma de organización interna de este grupo político y en la estabilidad lograda en el poder, especialmente por la producción de disciplina interna. 12. Como ha señalado Novaro (2011) este atributo cristalizó la identidad de esta fuerza política y se fue acentuando en el primer gobierno de Cristina Fernández de Kirchner (2007-2011), especialmente a partir del conflicto con las corporaciones agrarias.

13. Este rasgo del Frente para la Victoria, expresado en la dimensión discursiva de su principal líder, fue conceptualizado por Montero (2011) como un "ethos" militante. La autora definió esta característica como una identidad construida en relación con el pasado reciente y el pasado silenciado, especialmente ciertos hechos políticos significativos de la década de 1980. Bajo esta construcción identitaria, que contribuyó a despertar la creencia en la figura de Néstor Kirchner, identificó un conjunto de valores como aquellos que reivindican el "militante como hombre común", la "heroicidad", la "transgresión", "los sueños revolucionarios" y las "convicciones que se presentan como imposibles de abandonar".

\section{Bibliografía}

G. ABOY CARLÉS (2005), "Populismo y democracia en la Argentina contemporánea. Entre el hegemonismo y la refundación", en Estudios Sociales, XV, № 28.

F. AMATO y C. BOYANOVSKY BAZÁN (2008), Setentistas. De la Plata a la Casa Rosada, Buenos Aires, Sudamericana.

P. BOURDIEU (1981), "La representación política. Elementos para una teoría del campo político", en Actas de investigación en Ciencias Sociales, №36-37.

P. BOURDIEU (1984), "Espacio social y génesis de las clases”, en Sociología y Cultura, México DF, Grijalbo.

D. CABOT y F. OLIVERA (2007), Hablen con Julio. Julio De Vido y las historias ocultas del poder kirchnerista, Buenos Aires, Sudamericana.

E. CALVO (2005), “Argentina, elecciones legislativas 2005: consolidación institucional del kirchnerismo y territorialización del voto", en Revista de Ciencia Política, Vol. 25, № 2, [citado 2016-04-07]. Disponible en: http://dx.doi.org/10.4067/S0718-090X2005000200007.

M. DAGATTI (2013), "Contribuciones para una cartografía discursiva del kirchnerismo", en J. BALSA (Comp.), Discurso, política y acumulación en el kirchnerismo, Quilmes, Centro Cultural de la Cooperación Floreal Gorini y Universidad Nacional de Quilmes.

M. DE LUCA (2011), "Del príncipe y sus secretarios. Cinco apuntes sobre gabinetes presidenciales en la Argentina reciente", en A. MALAMUD y M. DE LUCA (Comps.), La política en tiempos de los Kirchner, Buenos Aires, Eudeba. 
L. DI MATTEO (2009), “Gracias, Néstor”. La politica de los negocios. Los socios del Holding Kirchner: Rudy Ulloa, Lázaro Báez, Cristóbal López, Enrique Eskenazi, Buenos Aires, Sudamericana.

R. GARGARELLA (2011), "Notas sobre kirchnerismo y Justicia”, en A. MALAMUD y M. DE LUCA (Comps.), La política en tiempos de los Kirchner, Buenos Aires, Eudeba.

V. GARRONE y L. ROCHA (2003), Néstor Kirchner. Un muchacho peronista y la oportunidad del poder, Buenos Aires, Planeta.

D. GATTI (2003), Kirchner, el amo del feudo, (S/D).

C. GERVASONI (2011), "La política provincial es política nacional: cambios y continuidades subnacionales del menemismo al kirchnerismo", en A. MALAMUD y M. DE LUCA (Comps.), La politica en tiempos de los Kirchner, Buenos Aires, Eudeba.

S. LEVITSKY Y V. MURILLO (2008), "Argentina: From Kirchner to Kirchner", en Journal of Democracy, $19, \mathrm{~N}^{\circ} 2$.

L. MAJUL (2009), El Dueño. La historia secreta de Néstor Kirchner, el hombre que maneja los negocios públicos y privados de la Argentina, Buenos Aires, Planeta.

D. MIGUEZ (2011), Kirchner íntimo. El hombre y el político, por el periodista que mejor lo conoció, Buenos Aires, Planeta.

S. MONTERO (2007), "Política y convicción. Memorias discursivas de la militancia setentista en el discurso presidencial argentino", en ALED, 7, (2).

S. MONTERO (2012), ¡Y al final un día volvimos! Los usos de la memoria en el discurso kirchnerista (2003-2007), Buenos Aires, Prometeo.

M. NOVARO (2011), "La cultura política y el sentido común bajo el kirchnerismo", en A. MALAMUD y M. DE LUCA (Comps.), La política en tiempos de los Kirchner, Buenos Aires, Eudeba.

M. O’DONNELL (2007), Propaganda K. Maquinaria de promoción con el dinero del Estado, Buenos Aires, Planeta.

A. PANEBIANCO (1990), Modelos de partido, Madrid, Alianza.

L. PERELMITER (2010), "Militar el Estado. La incorporación de movimientos sociales de desocupados en la gestión de políticas sociales. Argentina (2003-2008)", en A. MASSETTI, E. VILLANUEVA y M. GÓMEZ, Movilizaciones, protestas e identidades politicas en la Argentina del bicentenario, Buenos Aires, Nueva Trilce.

G. PÉREZ y A. NATALUCCI (2012), "El kirchnerismo como problema sociológico", en G. PÉREZ y A. NATALUCCI (Comps.), Vamos las bandas. Organizaciones y militancia kirchneristas, Buenos Aires, Nueva Trilce.

REVISTA TESIS. Publicación periodística de aparición bimensual con circulación en toda la provincia de Santa Cruz, impresa en Buenos Aires, años 1983-1987.

E. RINESI Y G. VOMMARO (2007), "Notas sobre la democracia, la representación y algunos problemas conexos", en E. RINESI, G. NARDACCHIONE y G. VOMMARO (Eds.), Los Lentes de Victor Hugo: transformaciones políticas y desafios teóricos en la Argentina recientes, Buenos Aires, UNGSPrometeo.

E. RINESI (2007), "Representatividad, legitimidad, hegemonía. Los dilemas de la representación política después del desbarajuste", en S. EMILIOZZI, M. PECHENY y M. UNZUÉ (Comps.), La dinámica de la democracia. Representación, instituciones y ciudadanía en Argentina, Buenos Aires, Prometeo.

E. RINESI, G. VOMMARO Y M. MURACA (Comps.) (2010), Si este no es el pueblo. Hegemonía, populismo y democracia en Argentina, Los Polvorines, Universidad Nacional de General Sarmiento, Instituto de Estudios y Capacitación, Federación Nacional de Docentes Universitarios.

D. ROCCA RIVAROLA (2014), "El libro «bueno» y el libro «malo» sobre La Cámpora: sus aportes para la investigación social sobre la militancia oficialista”, en Centro de Estudios Avanzados, № 31.

D. ROCCA RIVAROLA (2016), "Militancia institucionalizada: Testimonios de la militancia y el Estado en el kirchnerismo y los gobiernos del PT", Ponencia presentada en V Encuentro Internacional de Teoria y práctica política en América Latina. Nuevas y viejas desigualdades, Universidad Nacional de Mar del Plata.

S. RUSSO (2013), La presidenta. Historias de una vida, Buenos Aires, Sudamericana. 
B. SARLO (2011), La Audacia y el Cálculo, Buenos Aires, Sudamericana.

M. SERRAFERO (2011), "Presidencia y Vicepresidencia. Otra difícil combinación", en A. MALAMUD y M. DE LUCA (Comps.), La política en tiempos de los Kirchner, Buenos Aires, Eudeba.

A. SERVETTO (2010), 73/76: El gobierno peronista contra las provincias "montoneras", Buenos Aires, Siglo XXI.

P. SOSA (2014), "Desintegración social y poder político. Génesis y consolidación del Frente para la Victoria en la Provincia de Santa Cruz (1988-1996)", Tesis de Doctorado inédita, Facultad de Ciencias Sociales, UBA.

P. SOSA (2016), "La territorialización de la política a nivel subnacional. El caso del Partido Justicialista en Santa Cruz", en Revista Estudios, № 35, Universidad Nacional de Córdoba. Disponible en https://revistas.unc.edu.ar/index.php/restudios.

P. SOSA (2017a), "La génesis del Frente para la Victoria en Argentina (1988-1996)", en América Latina Hoy [En prensa].

P. SOSA (2017b), "Los dirigentes del Frente para la Victoria Santacruceña: una elite de militantes", en P. CANELO y M. HEREDIA (Comps.), Los puentes y las puertas: las fronteras de la política argentina a través de sus elites, Buenos Aires, [En prensa].

E. TENEMBAUM (2010), ¿Qué les pasó?, Buenos Aires, Sudamericana.

M. VÁZQUEZ Y P. VOMMARO (2012), "Con la fuerza de la juventud: aproximaciones a la militancia kirchnerista desde La Cámpora”, en G. PÉREZ y A. NATALUCCI (Comps.), Vamos las bandas. Organizaciones y militancia kirchneristas, Buenos Aires, Nueva Trilce.

M. VÁZQUEZ (2013), "En torno a la construcción de la juventud como causa pública durante el kirchnerismo: principios de adhesión, participación y reconocimiento", en Revista Argentina de Estudios de Juventud, $\mathrm{N}^{\circ} 1$.

J. VILABOA Y M. HUDSON (2016), "Santa Cruz: de la hegemonía política a la crisis de representación”, Ponencia presentada en las XI Jornadas de Investigadores en Historia, Mar del Plata, Universidad Nacional de Mar del Plata.

J. VILABOA y A. BONA (2017), "La renovación en Santa Cruz, 1983-1991", en M. FERRARI y V. MELLADO (Coords.), El peronismo en la historia reciente. Dilemas del momento renovador en clave subnacional (1983-1991), Caseros, EDUNTREF.

S. WALGER (2010), Cristina. De legisladora combativa a presidenta fashion, Buenos Aires, Ediciones B.

O. WORNAT (2005), Reina Cristina. Vida pública y privada de la mujer más poderosa de la Argentina, Buenos Aires, Planeta.

N. YABKOWSKI (2012), "La negación de la parte: La crisis de la representación política argentina", en Nómadas. Revista Crítica de Ciencias Sociales y Jurídicas. Número Especial: América Latina. Disponible en http://dx.doi.org/10.5209/rev_NOMA.2012.41784.

Recibido: 13/08/2015. Aceptado: 30/06/2016.

Pamela Sosa, "Los orígenes de las concepciones políticas del kirchnerismo. La experiencia política del Ateneo Juan Domingo Perón en la provincia de Santa Cruz (1981-1987)". Revista Temas y Debates. ISSN 1666-0714, año 20, número 32, julio-diciembre 2016, pp. 77-96. 